\title{
Sobre los autores
}

\author{
Alejandro Del Vecchio \\ Profesor en Letras por la Universidad Nacional \\ de Mar del Plata (UNMdP, Argentina). Se \\ desempeña desde 2017 como ayudante \\ graduado en la cátedra Literatura y Cultura \\ Latinoamericanas II y participa de la tercera \\ etapa de ejecución del proyecto de investiga- \\ ción "Latinoamérica y la contemporaneidad. \\ Relatos de las últimas décadas", dirigido por \\ la doctora Mónica Marinone, UNMdP.
}

\section{Bruno Crisorio}

Licenciado en Letras por la Universidad Nacional de La Plata (UNLP, Argentina). Becario en el CONICET por el proyecto "La lírica de Aldo Oliva [1927-2000]. Efectos de lo político en las relaciones entre poesía e historia argentina", dirigido por Miriam Chiani y Enrique Foffani. Adscripto a la Cátedra Teoría Literaria I de la Facultad de Humanidades y Ciencias de la Educación (UNLP), cuya titular es Miriam Chiani. Ha participado en el libro Cuadernos de teoría, dirigido por Miriam Chiani (Al Margen, 2014), y es compilador, junto con Eugenia Straccali, del libro Atlas de la poesía argentina (EdULP, 2017).

\section{Pedro Brum}

Doutor em Letras. Professor Titular Universidade Federal de Santa María (UFSM-Brasil). Bolsista produtividade do Conselho Nacional de Desenvolvimento Científico e Tecnológico (CNPqBrasil). Líder do Grupo de Pesquisa Literatura e História. Coordenador do Núcleo Literatura, Imaginarios, Estética y Cultura, da Asociación de Universidades Grupo Montevideo. Entre as publicações, destaque para Teorias do Romance, Relações entre ficção e história; Literatura, história e memória em Baú de ossos; Extensão do moderno na narrativa brasileira.

\section{Jorge H. Wolff}

Doutor em Literatura pela Universidade Federal de Santa Catarina (UFSC-Brasil). Professor e pesquisador em literatura brasileira e latino-americana e teoria literária na UFSC, Florianópolis, Brasil. Doutor em Literatura pela UFSC. Autor de Julio Cortázar. A viagem como metáfora produtiva (Florianópolis, Letras Contemporâneas, 1998) e Telquelismos latinoamericanos. La teoría crítica francesa en el entre-lugar de los trópicos (Buenos Aires, Grumo, 2009 - versão brasileira: Rio de Janeiro, Papeis Selvagens, 2017). É co-editor das revistas outra travessia e Landa (UFSC) e tradutor de literatura hispano-americana.

María Laura de Arriba

Doctora en Letras, se desempeña como investigadora y profesora Asociada en la Universidad Nacional de Tucumán (UNT, Argentina), tanto en la Facultad de Filosofía y Letras como en la Escuela de Cine, Video y Televisión. Forma parte del Comité Académico del Doctorado en Letras y del cuerpo estable de dicha carrera en el área de Literatura Latinoamericana. Asimismo, integra el Comité Académico del Doctorado en Humanidades de la misma Facultad. 
Ha dictado cursos y conferencias en diversas universidades norteamericanas y europeas como Brandeis, Brown, Smith College, Biblioteca del Congreso (Washington DC), Complutense de Madrid, KöIn (Alemania) y Jaguelónica de Cracovia. Ha publicado numerosos artículos en revistas especializadas argentinas y del exterior sobre literatura latinoamericana, escritura autobiográfica y discursividad colonial.

\section{Miriam Gárate}

Profesora del Departamento de Teoría Literaria de la Universidade Estadual de Campinas (UNICAMP, Brasil). Ha investigado las relaciones entre prácticas letradas y cine en América Latina, durante el período silente. Algunas publicaciones sobre el tema son: Películas de papel/crónicas de celuloide. Acerca de João do Rio, Alcântara Machado y Alberto Cavalcanti (Santiago, 2012), Películas de papel: cine y literatura en dos textos latinoamericanos de la década del veinte (La Plata, 2014), Primer cine y retórica del viaje en tres crónicas latinoamericanas de pasaje de siglo: 1896/1913 (Montevideo, 2015), Latinoamericanos en Hollywood: sueños, realidades y clichés de la ficción (Santiago, 2016), Entre a letra e a tela. Literatura, imprensa e cinema na América Latina: 1896-1932 (2017).

\section{Sara Rojo}

Universidade Federal de Minas Gerias (UFMG, Brasil). Conselho Nacional de Desenvolvimento Científico e tecnológico (CNPq, Brasil). Fundação de Amparo à Pesquisa de Minas Gerais (Fapemig).

Graduación en Letras por la Pontificia Universidad Católica de Chile (1979), magister (Master of Arts) por la State University of New York (1989), Magister en Letras Hispánicas por la Pontificia Universidad Católica de Chile (1985) y doctorado en Literaturas Hispánicas por la
State University of New York (1991). Posdoctorados en la Università degli Studi di Bologna (2001) y en la Universidad de Chile (2007). Actualmente es becaria de productividad del CNPq y cuenta con el apoyo de la Fapemig en su calidad de Pesquisadora Mineira. Profesora Titular de la Universidade Federal de Minas Gerais y Coordinadora de la Câmara de Pesquisa da Faculdade de Letras / UFMG. Su último libro fue publicado en 2016, Teatro LatinoAmericano em diálogo: produção e visibilidade.

\section{Mariana Bonano}

Profesora, licenciada y doctora en Letras (Orientación Literatura) por la Universidad Nacional de Tucumán (UNT, Argentina). Investigadora Adjunta del Consejo Nacional de Investigaciones Científicas y Técnicas (CONICET, Argentina). Se desempeña como Profesora adjunta en las cátedras «Periodismo", "Producción Periodística" y "Seminario de Trabajo Final" de la carrera de Ciencias de la Comunicación de la Universidad Nacional de Tucumán. Integra el proyecto de investigación PIUNT H607 «Lecturas del presente. Realismos y construcción de realidades en la cultura latinoamericana (literatura, cine, producción audiovisual)", dirigido por la Dra. María Laura de Arriba y subsidiado por el Consejo de Ciencia y Técnica de la UNT, así como el Nodo Tucumán de la Red Académica Interuniversitaria de Docencia e Investigación en el área de la literatura y de la cultura latinoamericana KATATAY. Fue becaria del CIUNT y becaria doctoral y postdoctoral del CONICET. Obtuvo además dos becas de movilidad profesional otorgadas por el Ministerio de Educación de la República Argentina en 2010, y el programa ISAP (Alemania) en 2015, respectivamente. Ha difundido numerosos artículos sobre literatura y crítica literaria en compilaciones y revistas especializadas, en particular sobre la producción de Francisco Urondo y la intelectualidad argen- 
tina de 1960, así como sobre problemáticas inherentes a la prensa y al rol de los medios en la sociedad y en particular, sobre el periodismo narrativo latinoamericano.

\section{Carlos Ávila}

Licenciado en Letras de la Universidad Central de Venezuela y Magister en Literaturas Española y Latinoamericana de la Universidad de Buenos Aires. Actualmente reside en la ciudad de Buenos Aires, Argentina. Adscripto a proyecto de investigación en la Universidad Nacional de Mar del Plata (UNMdP, Argentina)

\section{Julieta Viu Adagio}

Doctora en Letras. Fue becaria doctoral del CONICET, Argentina. Doctoranda del Doctorado en Humanidades y Artes con mención en Literatura en la Universidad Nacional de Rosario (UNR, Argentina). Integra equipos de investigación en el área de literatura latinoamericana. Se desempeña como Adscripta en la Cátedra de Literatura Iberoamericana I de la Facultad de Humanidades y Artes de la Universidad Nacional de Rosario. Ha publicado artículos en revistas nacionales e internacionales. Es miembro de la Red Académica de Docencia e Investigación en Literatura Latinoamericana Katatay.

\section{Alejandra Cecilia Carril}

Profesora en Historia por la Facultad de Humanidades y Ciencias de la Universidad Nacional del Litoral (FHUC-UNL, Argentina). Diplomada en Ciencias Sociales con especialización en Educación, imágenes y medios por la Facultad Latinoamericana de Ciencias Sociales (FLACSO, Argentina) y Doctoranda en Ciencias Sociales por la Universidad Nacional de Entre Ríos. Se desempeña actualmente como docente universitaria y en institutos de educación superior en las cátedras de Sociología de la Cultura y Metodología de
Investigación Social. Es miembro del Centro de Investigación en Estudios Culturales, Educativos, Históricos y Comunicacionales de la FHUC-UNL y de la Asociación Argentina de Estudios sobre Cine y Audiovisual.

\section{Mariné Nicola}

Profesora en Historia (Facultad de Humanidades y Ciencias, Universidad Nacional del Litoral, FHUC-UNL, Argentina). Especialista en Docencia Universitaria (FHUC-UNL). Doctoranda en Ciencias Sociales por la Universidad Nacional de Entre Ríos (UNER, Argentina). Se desempeña como docente universitaria en la Cátedra "Sociología de la Cultura" de la FHUC-UNL; en la Cátedras "Antropología Cultural y Social" y "Sociología del Trabajo" de la Escuela Superior de Sanidad «Dr. Ramón Carrillo", Facultad de Bioquímica y Ciencias Biológicas pertenecientes a la UNL.

Desde el año 2002 participa como investigadora en distintos proyectos $\mathrm{CAI}+\mathrm{D}$ aprobados y financiados por la UNL relacionados al cine, la historia, los derechos humanos y la memoria. Actualmente se desempeña como co-directora del Proyecto CAI+D 2016 "Historias, memorias y representaciones del pasado reciente: gubernamentalidades, violencia política y derechos humanos" dirigido por el Dr. Luciano Alonso.

Es integrante de la Junta directiva del Centro de Investigaciones en Estudios Culturales, Educativos, Históricos y Comunicacionales (CIECEHC, FHUC-UNL).

Es miembro activa de la Asociación Argentina de Estudios sobre Cine y Audiovisual (AsAECA). Es miembro de la Junta Departamental del Departamento de Historia. FHUC-UNL. Ha participado como organizadora, coordinadora, comentarista y expositora de trabajos en múltiples congresos, jornadas y eventos científicos nacionales e internacionales. Ha publicado artículos en libros y revista especia- 
lizadas en temas relacionados al cine, políticas culturales, memoria, derechos humanos e historia. Es directora y coordinadora general de la Revista Culturas. Debates y perspectivas de un mundo en cambio. Facultad de Humanidades y Ciencias. UNL.. Es coordinadora del Archivo audiovisual AyMA -Archivo y Memoria Audiovisual del Centro de Investigaciones en Estudios Culturales, Educativos, Históricos y Comunicacionales (CIECEHC, FHUC-UNL).

\section{Natacha Scherbovsky}

Magister en Antropología Visual (FLACSO, Ecuador). Lic. en Antropología (Universidad Nacional de Rosario, UNR). Realizadora audiovisual. Prof. de la cátedra "Antropología Visual" en la Facultad de Humanidades y Artes de la Universidad Nacional de Rosario (UNR- Argentina). Adscripta a la cátedra "Historia Social Latinoamericana " (Facultad de Humanidades y Artes, UNR). Organizadora del Cine Club del Espacio Cultural Mascaró Rosario. Miembro de la revista digital La Tinta, periodismo hasta mancharse (Sección de cultura "Gilda").

\section{Liliana Zimmermann}

Profesora en Letras (Universidad Católica de Santa Fe). Magister en Didácticas Específicas (Universidad Nacional del Litoral). Se desempeña en la Facultad de Humanidades y Ciencias de la Universidad Nacional del Litoral (FHUCUNL, Argentina) en el cargo de jefe de Trabajos prácticos en las asignaturas Gramática de Español, Lingüística Textual y Pragmática. Forma parte del Comité académico de la especialización a distancia: Licenciatura de enseñanza de la Lengua y la Literatura, en la cual dicta el seminario Teorías Lingüísticas I. Ha publicado artículos en libros de la especialidad y ha participado de eventos académicos con ponencias relacionadas. Actualmente se desempeña como parte del grupo responsable del Proyecto CAl+D 2016, titulado: "Variación Lingüística.

Estudio microparamétrico de las gramáticas del español actual de Santa Fe y Paraná", dirigido por Dra. Cadina Palachi. Es doctorando en el Doctorado en Humanidades de la UNL.

\section{Eduardo Toro}

Doctorando en Teoría e Historia Literaria en la Universidade Estadual de Campinas (UNICAMP, Brasil). Realizó un período de intercambio en la Universidad de la República, Montevideo, Uruguay (UdelaR, 2016), donde tuvo la oportunidad de trabajar con el archivo personal de Ángel Rama. Actualmente adelanta una investigación sobre los tránsitos conceptuales entre Antonio Candido y Ángel Rama.

\section{Hernán Morales}

Magíster en Letras Hispánicas, Profesor en Letras (Universidad Nacional de Mar del Plata, UNMdP, Argentina). Es miembro del Centro de Letras Hispanoamericanas (CELEHIS), UNMdP. Miembro del Grupo Literatura y Cultura Latinoamericanas.

\section{María Valentina Morande}

Técnica universitaria en Comunicación Social con mención en Redacción por la Universidad Nacional de Entre Ríos (UNER, Argentina). Estudiante del Profesorado y la Licenciatura en Letras en la Facultad de Humanidades y Ciencias de la Universidad Nacional del Litoral (FHUC-UNL, Argentina).

\section{María Laura Kiener}

Estudiante del Profesorado y la Licenciatura en Letras en la Facultad de Humanidades y Ciencias de la Universidad Nacional del Litoral (FHUC-UNL, Argentina).

\section{Lara Yost}

Estudiante del Profesorado en Letras en la Facultad de Humanidades y Ciencias de la Universidad Nacional del Litoral (FHUC-UNL, Argentina). 


\section{Convocatoria de artículos}

La revista Culturas. Debates y perspectivas de un mundo en cambio convoca al envío de artículos inéditos a publicarse en su número No I4, bajo el eje: Consumos culturales, políticas públicas, instituciones y públicos.

\section{Características de las colaboraciones}

Los artículos o notas deberán sujetarse a lo establecido en el documento «Requisitos para las colaboraciones» en la página de la Biblioteca Virtual de unL y enviarse a los correos electrónicos de la revista:

marinenicola@yahoo.com.ar;

mnicola@fhuc.unl.edu.ar;

revistaculturas@fhuc.unl.edu.ar;

hasta el día 25 de Octubre de 2019. Cada trabajo será evaluado por el Consejo de Redacción y Evaluadores Externos, quienes podrán aceptarlo o rechazarlo.

Para consultar los números anteriores de la publicación ingresar a http://bibliotecavirtual.unl.edu.arl publicaciones/index.php/Culturas.

\section{Secciones}

I. Artículos: Para nuestro próximo número deberán tratar problemáticas afines a los conceptos mencionados en el eje temático, en este caso «Consumos culturales, políticas públicas, instituciones y públicos» y podrán ser abordados desde diferentes perspectivas: históri- 
cas, sociológicas, antropológicas, políticas, artísticas, comunicacionales, etc. poniendo en relación al menos dos de ellas.

2. Reseńas y comentarios: Podrán ser reseńas de producciones culturales de diversa índole, como libros, filmes, videos, exposiciones artísticas (escultura, pintura, fotografía, entre otros), priorizando las desarrolladas en el ámbito local y regional.

\section{Requisitos para las colaboraciones}

I. Los artículos que se envíen para ser publicados deberán ser acordes a las secciones y/o líneas temáticas de la convocatoria correspondiente; asimismo, deberán ser inéditos y en idioma español. La versión digital de los trabajos enviados serán documentos en formato .doc, .rtf o similar (no pdf).

2. Cada artículo deberá contener una portada con: Título, Autor, Unidad académica a la que pertenece, investigación y sede de trabajo, si corresponde. Datos del autor: nombre, título e institución otorgante, dirección, teléfono y correo electrónico junto con un cv breve (no más de 200 palabras).

3. El texto comienza con Título; Autor; Pertenencia institucional; Resumen/Abstract/ Resumo (en español, en inglés y en portugués hasta 150 palabras) Palabras clave / Key words/ Palavras-chave (5 como máximo)

4. Los textos, en lo posible, tendrán interlineado simple, letra Times New Roman, cuerpo I2, y márgenes razonables.

5. Los «Artículos» tendrán una extensión máxima de 6000 palabras, incluyendo texto e imágenes, si es necesario. Los trabajos destinados a «Comentarios» deberán tener una extensión máxima de hasta 3000 palabras y las «Reseñas» deberán tener una extensión máxima de hasta 2000 palabras. 
6. Las imágenes (fotos, tablas, cuadros, mapas, etc.) deberán enviarse por separado, en un archivo para cada una, en formato .jpg con una resolución mínima de $300 \mathrm{dpi}$. 7. Los editores no son responsables de la localización o calidad de las imágenes que acompañen los artículos. Las imágenes, fotos, cuadros y gráficos enviados por separado del texto, numerados y titulados correctamente en archivo adjunto.

8. La revista Culturas no se hace responsable por los trabajos no publicados ni se obliga a mantener correspondencia con los autores sobre las decisiones de selección.

Se sugiere consultar el "Instructivo de estilo" y «Reglamento de publicaciones» de Ediciones UNL en la siguiente dirección electrónica: www.unl.edu.arleditoriall

\section{Nota aclaratoria}

Sólo se aceptarán los artículos que satisfagan todos los requisitos aquí señalados. Los trabajos estarán sujetos a una primera revisión de la Dirección de la revista y del Comité de Redacción, para corroborar el cumplimiento de los requisitos aquí expuestos, y a dictámenes posteriores de Evaluadores externos, considerando la pertinencia temática y sus contenidos académicos y formales. Las colaboraciones aceptadas se someterán a correcciones conjuntas con el/los autor/es y su publicación estará sujeta a la disponibilidad de espacio en cada número. El envío de cualquier colaboración a la revista implica no sólo la aceptación de lo establecido en este documento, sino también la autorización a la Universidad Nacional del Litoral para editar, re-editar, publicar, reproducir, difundir, distribuir copias, preparar trabajos derivados, en soporte de papel, electrónicos o multimedia, o cualquier otro creado o a crearse e incluir el artículo en índices nacionales e internacionales o bases de datos, como también en cualquier otra forma de publicación existente o que exista en el futuro, con la única con- 
dición de la mención expresa de los autores, y además autorizando a la Universidad Nacional del Litoral a utilizar sus nombres y eventualmente sus imágenes para incluirlas en la publicación de la obra.

Para cualquier consulta dirigirse a los siguientes mails:

marinenicola@yahoo.com.ar;

mnicola@fhuc.unl.edu.ar;

revistaculturas@fhuc.unl.edu.ar. 